\title{
Spatial and temporal expression of immunoglobulin superfamily member 1 in the rat
}

\author{
Sjoerd D Joustra ${ }^{1,2}$, Onno C Meijer ${ }^{2}$, Charlotte A Heinen ${ }^{3,4}$, Isabel M Mol ${ }^{2}$, \\ El Houari Laghmani ${ }^{1}$, Rozemarijn M A Sengers ${ }^{1}$, Gabriela Carreno ${ }^{5}$, \\ A S Paul van Trotsenburg ${ }^{3}$, Nienke R Biermasz ${ }^{2}$, Daniel J Bernard ${ }^{6}$, Jan M Wit', \\ Wilma Oostdijk', Ans M M van Pelt' ${ }^{7}$, Geert Hamer ${ }^{7}$ and Gerry T M Wagenaar ${ }^{1}$ \\ ${ }^{1}$ Department of Pediatrics, Leiden University Medical Center, Leiden, The Netherlands \\ ${ }^{2}$ Department of Medicine, Division of Endocrinology, Leiden University Medical Center, Leiden, The Netherlands \\ ${ }^{3}$ Department of Pediatric Endocrinology, Emma Children's Hospital, Academic Medical Center, Amsterdam, \\ The Netherlands \\ ${ }^{4}$ Endocrinology and Metabolism, Academic Medical Center, The Netherlands \\ ${ }^{5}$ Developmental Biology and Cancer Programme, Institute of Child Health, London, UK \\ ${ }^{6}$ Department of Pharmacology and Therapeutics, McGill University, Montreal, Quebec, Canada \\ ${ }^{7}$ Center for Reproductive Medicine, Women's and Children's Hospital, Academic Medical Center, \\ Amsterdam, The Netherlands
}

\author{
Correspondence \\ should be addressed \\ to S D Joustra \\ Email \\ s.d.joustra@lumc.nl
}

\begin{abstract}
Loss-of-function mutations in the immunoglobulin superfamily member 1 (IGSF1) gene cause an X-linked syndrome of central hypothyroidism, macroorchidism, variable prolactin and GH deficiency, delayed pubertal testosterone rise, and obesity. To understand the pathophysiology of this syndrome, knowledge on IGSF1's place in normal development is imperative. Therefore, we investigated spatial and temporal protein and mRNA expression of IGSF1 in rats using immunohistochemistry, real-time quantitative PCR (qPCR), and in situ hybridization. We observed high levels of IGSF1 expression in the brain, specifically the embryonic and adult choroid plexus and hypothalamus (principally in glial cells), and in the pituitary gland (PIT1-lineage of GH, TSH, and PRL-producing cells). IGSF1 is also expressed in the embryonic and adult zona glomerulosa of the adrenal gland, islets of Langerhans of the pancreas, and costameres of the heart and skeletal muscle. IGSF1 is highly expressed in fetal liver, but is absent shortly after birth. In the adult testis, IGSF1 is present in Sertoli cells (epithelial stages XIII-VI), and elongating spermatids (stages X-XII). Specificity of protein expression was corroborated with Igsf1 mRNA expression in all tissues. The expression patterns of IGSF1 in the pituitary gland and testis are consistent with the pituitary hormone deficiencies and macroorchidism observed in patients with IGSF1 deficiency. The expression in the brain, adrenal gland, pancreas, liver, and muscle suggest IGSF1's function in endocrine physiology might be more extensive than previously considered.
\end{abstract}

\footnotetext{
Key Words

- expression profiling

- rat

- hypothalamus

- choroid plexus

- pituitary gland

testis
}

http://joe.endocrinology-journals.org DOI: $10.1530 / J O E-15-0204$
(C) 2015 Society for Endocrinology Printed in Great Britain
Published by Bioscientifica Ltd
Journal of Endocrinology (2015) 226, 181-191 


\section{Introduction}

Loss-of-function mutations or deletions in immunoglobulin superfamily member 1 (IGSF1) cause an X-linked endocrine syndrome characterized by congenital hypothyroidism of central origin and macroorchidism in male patients (Sun et al. 2012). In addition, a proportion of affected males show prolactin deficiency, partial and transient GH deficiency, disharmonious pubertal development (i.e., normal timing of testicular growth but delayed rise of testosterone), high insulin-like growth factor1 in middle age, and increased BMI and fat percentage (Joustra et al. 2013). A minor proportion of heterozygous female carriers exhibit central hypothyroidism and/or prolactin deficiency (Joustra et al. 2013). Igsf1-deficient male mice similarly show central hypothyroidism and increased body mass (Sun et al. 2012).

IGSF1 encodes a plasma membrane immunoglobulin superfamily glycoprotein (Frattini et al. 1998, Mazzarella et al. 1998). The canonical IGSF1 protein possesses 12 immunoglobulin-like loops of the constant region type 2 (C2), a transmembrane domain, and a short intracellular C-terminal tail. A hydrophobic linker, separating loops 5 and 6 , targets the protein for obligate co-translational proteolysis such that only the C-terminal domain (CTD) traffics to the plasma membrane (Robakis et al. 2008). Previously described IGSF1 mutations impair trafficking of the CTD to the cell surface in heterologous cells (Sun et al. 2012).

The full spectrum of signs and symptoms of this novel endocrine syndrome, as well as its pathophysiology, currently remain speculative. This stems from our incomplete understanding of IGSF1's function and expression both in adulthood and during development. We therefore investigated the spatial and temporal patterns of IGSF1 protein and mRNA expression in the rat.

\section{Materials and methods}

\section{Animals}

The research protocol was approved by the Institutional Animal Care and Use Committees of the Leiden University Medical Center and the Academic Medical Center in Amsterdam. Wistar rats were kept in a controlled darklight cycle (12 h light:12 h darkness), and had access to water and pellet food ad libitum. Timed-pregnant rats were bled by decapitation on day 15 after conception and embryos were removed from the uterus and fixed for $24 \mathrm{~h}$ in cold buffered formaldehyde (4\% paraformaldehyde in PBS, pH 7.4; PFA). Adult 7-week-old female and male rats (a minimum of four animals per organ) were anesthetized with an intraperitoneal injection of ketamine $(25 \mathrm{mg} / \mathrm{kg}$ body weight; Nimatek, Eurovet Animal Health BV, Bladel, The Netherlands) and xylazine $(50 \mathrm{mg} / \mathrm{kg}$ body weight; Sedamun, Eurovet Animal Health BV). After $5 \mathrm{~min}$, rats were exsanguinated by transection of the abdominal blood vessels. The organs were removed and fresh frozen in liquid nitrogen for real-time qPCR and in situ hybridization. For immunohistochemistry and immunofluorescence, organs were fixed for $24 \mathrm{~h}$ in cold PFA (or 70\% diluted Bouin's solution for testis) and embedded in paraffin after dehydration in a graded alcohol series and xylenes.

\section{Real-time qPCR}

Relative Igsf1 mRNA expression was assessed in various organs (four to six animals, both sexes), as well as punches from choroid plexus (lateral ventricle of the brain), hypothalamus (paraventricular nucleus), and dorsal brain cortex (three animals, both sexes). Punches were taken with a Harris UniCore hollow needle (Electron Microscopy Sciences; $1.2 \mathrm{~mm}$ internal diameter) from $200 \mu \mathrm{m}$ thick transverse sections at around $1.53 \mathrm{~mm}$ caudal to Bregma (Paxinos \& Franklin 1988). Total RNA was isolated from tissue homogenates using acid guanidinium thiocyanatephenol-chloroform extraction and isopropanol precipitation (RNA-Bee, Tel-Test, Inc, Bio-Connect BV, Huissen, The Netherlands). The RNA sample $(2 \mu \mathrm{g})$ was dissolved in RNase-free water and quantified spectrophotometrically in a final volume of $20.5 \mu \mathrm{l}$. The integrity of the RNA was studied by gel electrophoresis on a $1 \%$ agarose gel containing ethidium bromide. Samples did not show degradation of ribosomal RNA by visual inspection under ultraviolet light. First-strand cDNA synthesis was performed with the SuperScript Choice System (Life Technologies) by oligo(dT)12-18 priming as described previously (Wagenaar et al. 2004). For qPCR, $1 \mu$ l of firststrand cDNA diluted 1:10 in RNase-free water was used in a total volume of $25 \mu \mathrm{l}$, containing $12.5 \mu \mathrm{l} 2 \times$ SYBR Green PCR Master Mix (Applied Biosystems) and $200 \mathrm{ng}$ of each primer. PCR reactions were performed using the following conditions: $95^{\circ} \mathrm{C}$ for $10 \mathrm{~min}$ (one cycle), $94{ }^{\circ} \mathrm{C}$ for $15 \mathrm{~s}$, and $60^{\circ} \mathrm{C}$ for $1 \mathrm{~min}$ (40 cycles) on a Light Cycler 480 (Roche) of the Leiden Genome Technology Center (Leiden, The Netherlands), as described previously (Wagenaar et al. 2013). Data were analyzed with the Light Cycler 480 Software version 1.5.0 and quantified with the

Published by Bioscientifica Ltd. 
comparative threshold cycle method using $\beta$-actin as a housekeeping gene reference (Pfaffl 2001). Using Primer Express Software package (Applied Biosystems), specific primers were designed for Igsf1 (TGTGGCTTCTAATCACAGCAA, GGGTGATATCCTTTCCTAGTTTGA) and Actb (TTCAACACCCCAGCCATGT, AGTGGTACGACCAGAGG CATACA).

\section{Immunohistochemistry and immunofluorescence}

Tissues in which Igsf1 mRNA was expressed were then examined using immunohistochemistry or immunofluorescence. These included embryonic tissues, brain, pituitary, adrenal gland, pancreas, liver, left ventricle of the heart, and skeletal muscle (see below for testis). Serial $4 \mu \mathrm{m}$ thick sections from formalin-fixed, paraffin-embedded tissue were mounted onto SuperFrost plus coated slides (Menzel-Gläzer, Braunschweig, Germany). After deparaffinization in xylenes and $100 \%$ ethanol, sections were incubated with $0.3 \% \mathrm{H}_{2} \mathrm{O}_{2}$ in methanol for $15 \mathrm{~min}$ to block endogenous peroxidase activity. After a graded alcohol series, sections were boiled in $0.01 \mathrm{M}$ sodium citrate ( $\mathrm{pH}$ 6.0) for $10 \mathrm{~min}$. Sections were incubated overnight with rabbit polyclonal anti-mouse IGSF1-CTD antibody (diluted 1:16 000, kindly provided by P. Scheiffele (Robakis et al. 2008), University of Basel, Basel, Switzerland), incubated with EnVision-HRP as recommended by the manufacturer (Dako, Glostrup, Denmark), stained with the chromogenic substrate NovaRed as instructed by the manufacturer (Vector Laboratories, Burlingame, CA, USA), and counterstained with hematoxylin. Primary antibodies were diluted in $\mathrm{PBS} / 1 \% \mathrm{BSA}$, fraction V (Roche Diagnostics).

Pituitary sections were incubated with the IGSF1 antibody, as well as a rabbit polyclonal anti-mouse PIT1 antibody (diluted 1:1000, gift from S. Rhodes (Voss et al. 1991), Indiana University, USA) as a marker of GH, TSH, and prolactin-producing cells, rabbit TPIT antibody (diluted 1:200, Cortex Biochem \#1603, San Leandro, CA, USA) as a marker of corticotropes, mouse SF1 antibody (diluted 1:200, Invitrogen \#N1665) as a marker of gonadotropes, or mouse LH antibody (diluted 1:200, National Hormone and Peptide Program \#AFPC697071P, Torrance CA, USA). IGSF1 and TPIT or PIT1 antibodies were visualized using biotinylated goat antirabbit (diluted 1:250, Dako Denmark A/S \#E0432) and the red fluorescent label streptavidin 555 (diluted 1:500, Life Technologies \#S-32355); IGSF1 and LH with biotinylated goat anti-rabbit IgG and streptavidin 555 (IGSF1), or the green fluorescent label Alexa Fluor 488 mouse IgG (diluted
1:300, Life Technologies \#A-11001) (LH); and IGSF1 and SF1 with the green fluorescent label Alexa Fluor 488 rabbit IgG (diluted 1:300, Life Technologies \#A-31565) (IGSF1) and biotinylated goat anti-mouse IgG (diluted 1:250, Dako Denmark A/S \#E0354) with streptavidin 555 (SF1).

For testis, serial sections ( $5 \mu \mathrm{m}$ thick) from diluted Bouin's-fixed, paraffin-embedded tissue were mounted on glass slides coated with $0.02 \%$ poly-L-lysine. After deparaffinization, sections were incubated with $0.3 \% \mathrm{H}_{2} \mathrm{O}_{2}$ in methanol for $15 \mathrm{~min}$ to block endogenous peroxidase activity. Nonspecific binding of the secondary antibody was blocked using $5 \%$ goat serum (Vector Laboratories) and $0.1 \%$ acetylated BSA (Vector Laboratories). Sections were incubated overnight at $4{ }^{\circ} \mathrm{C}$ in a humidified chamber with rabbit polyclonal anti-mouse IGSF1-CTD antibody (diluted $1: 500$ ) in $0.1 \%$ BSAc in PBS. Equivalent concentrations of rabbit IgG (Vector Laboratories) with 0.1\% BSAc were used for negative controls of the primary antibody, which resulted in no specific staining. After washing in PBS, the sections were incubated in the biotinylated secondary antibody goat anti-rabbit (Vector Laboratories). The sections were subsequently incubated for $60 \mathrm{~min}$ with avidin-biotinylated horseradish peroxidase complex (Vector Laboratories) and stained using the chromogenic substrate diaminobenzidine $(0.5 \mathrm{mg} / \mathrm{ml}$ 3,3-diaminobenzidine tetrahydrochloride dihydrate; LabVision ThermoFisher Scientific, Waltham, MA USA) with 0.034\% $\mathrm{H}_{2} \mathrm{O}_{2}$. Sections were counterstained with hematoxylin.

\section{In situ hybridization}

In situ hybridization was used to corroborate characteristic spatial protein expression patterns in endocrine tissues and assess localization of Igsf1 mRNA in different hypothalamic cell types.

Fresh frozen sections of $12 \mu \mathrm{m}$ were cut on a cryostat, thaw-mounted onto SuperFrost plus coated slides (Menzel-Gläzer), and stored at $-80^{\circ} \mathrm{C}$ until hybridization.

The in situ hybridization procedure was performed using Quantigene ViewRNA (Affymetrix, Santa Clara, CA, USA) according to the manufacturer's instructions. Briefly, upon fixation in 4\% PFA, washing, and dehydration in ethanol, sections were digested at $40^{\circ} \mathrm{C}$ for $20 \mathrm{~min}$ in protease XXIV (Protease QF, Affymetrix) and hybridized for $3 \mathrm{~h}$ at $40{ }^{\circ} \mathrm{C}$ with an Affymetrix probe against Igsf 1 (catalog\# VC1-14522, diluted 1:40). Brain sections were additionally hybridized with one of the following hypothalamic marker probes (all diluted 1:40): Tyrosine hydroxylase (Th, dopamine-producing cells, catalog\# VC6-15462), Somatostatin (catalog\# VC6-15126), Gnrh1

Published by Bioscientifica Ltd. 
(catalog\# VC6-15463), Ghrh (catalog\# VC6-15466), Crh (catalog\# VC6-15465), Trh (catalog\# VC6-15464), Glutamic acid decarboxylase 67 (Gad67, GABAergic cells, catalog\# VC6-11479), Vesicular glutamate transporter (Vglut, glutamatergic cells, catalog\# VC6-15119), Glial fibrillary acidic protein (GFAP, glial cells, catalog\# VC611478), and Vimentin (tanycytes, catalog\# VC6-16331). All probes were fragments of the full length RNA sequence.

The hybridized probes were pre-amplified and subsequently amplified according to the manufacturer's protocol. Next, label probe oligonucleotides conjugated to alkaline phosphatase type 1 were hybridized to the corresponding amplifier molecule, followed by Fast Blue and Fast Red substrates. Slides were counterstained briefly with Mayer's hematoxylin and embedded with DAPIcontaining aqueous mounting medium (Vectashield, catalog\# H-1500; Vector Laboratories, Peterborough, UK) or Innovex Advantage (Innovex, catalog\# NB300, Richmond, CA, USA).

\section{Analysis of co-localization in hypothalamus and pituitary gland}

Photographs were taken with a Coolsnap HQ2 camera (Photometrics, Tucson, AZ, USA) on a DM5500 microscope (Leica, Wetzlar, Germany), using a 560$580 \mathrm{~nm}$ band-pass excitation filter for the Igsf1 probe, and 672-747 nm for the hypothalamic cell type markers. The paraventricular nuclei were used to assess colocalization of Igsf1 with Crh, Sst, and Ghrh. Trh neurons are found in all parvocellular subdivisions of the PVN, but the hypophysiotropic Trh neurons are exclusively located in the medial and periventricular subdivisions at the mid and caudal levels of the PVN (Fekete \& Lechan 2014), and these regions were analyzed. The arcuate nuclei were used for the co-localization of Igsf1 with Ghrh and Th, the medial preoptic area for Igsf1 with Gnrh1, the tanycytes lining the third ventricle for Igsf1 and Vimentin, and the entire hypothalamus for Igsf1 with Vglut, Gfap, and Gad67.

Region of interest (ROI) analysis in ImageJ (National Institutes of Health, Bethesda, MD, USA) was used to mark cells or small regions positive for a marker. A median number of 222 ROI per marker were analyzed (lowest: 43, GHRH) from multiple animals.

Markers of neurosecretory cells (Crh, Sst, Th, Ghrh, Gnrh1, and Trh) and Vimentin filled most of the cell's cytoplasm (on average $70.0 \pm 18.7 \%$ of the ROI at $40 \times$ magnification). A threshold of $30 \%$ for an ROI positive for the marker was used. Markers for Gad67, Vglut, Gfap, and Igs $f 1$ showed a more diffuse signal (on average $32.3 \pm 9.3 \%$ of the ROI at $16 \times$ magnification). For these markers, a threshold of $15 \%$ was used. The percentage of cells with co-localization was calculated per animal.

For the pituitary gland, SF1, TPIT and PIT1 immunostaining were confined to the cell nucleus, while LH and IGSF1 showed a cytoplasmic staining pattern. Therefore, co-localization analysis was based on visual assessment of 300 cells per marker.

\section{Results}

\section{Brain and pituitary gland}

Igsf1 mRNA expression was observed in the adult brain, with highest levels in the hypothalamus and choroid plexus, and in the adult pituitary gland (Fig. 1).

Using immunohistochemistry, we observed in the embryonic day (ED) 15 brain the highest levels of IGSF1 protein expression in the epithelial cells of the choroid plexus (Fig. 2A and C) at the apical side facing the lateral and third ventricles. A similar pattern of IGSF1 expression was observed in adult choroid plexus at the protein (Fig. 2D) and mRNA levels (Fig. 2E).

In addition, we observed a heterogeneous pattern of IGSF1 protein expression in Rathke's pouch on ED15 (Fig. 2A and $\mathrm{B})$, with highest expression in the cells facing the lumen of the developing anterior pituitary gland. In the adult rat, we observed a heterogeneous pattern of IGSF1 protein and mRNA throughout the anterior pituitary gland (Fig. 3A and B) and hypothalamus (Fig. 3C). The highest hypothalamic expression was seen in the periventricular zone (e.g., in the median preoptic nucleus, periventricular nucleus, suprachiasmatic nucleus, arcuate nucleus) and medial zone

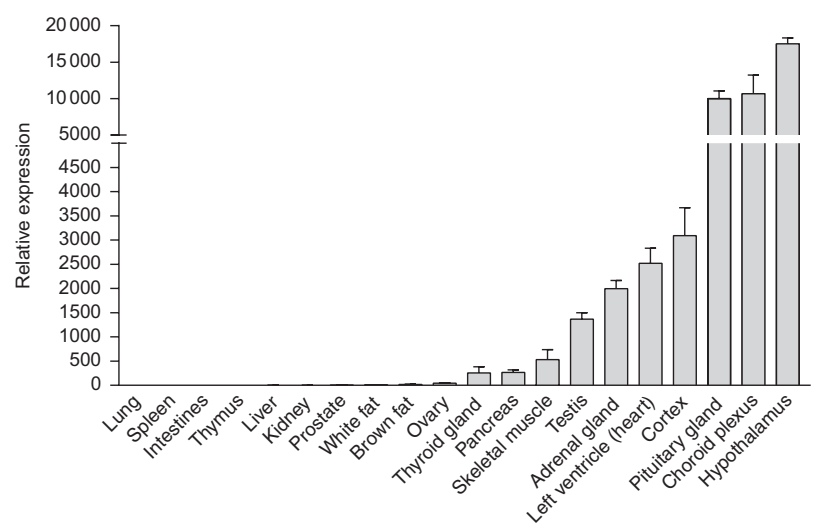

Figure 1

Relative Igsf1 mRNA expression in various organs of the adult rat assessed by $\mathrm{qPCR}$. $\beta$-actin was used as an internal control.

Published by Bioscientifica Ltd 

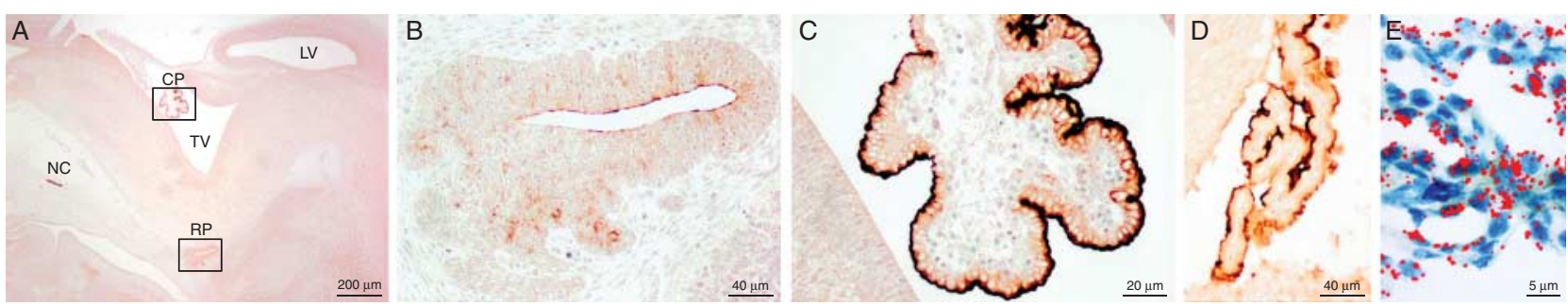

Figure 2

IGSF1 immunohistochemical staining was observed in the rat brain at embryonic day 15 , specifically in Rathke's pouch ( $A$ and $B$ ) and the choroid plexus ( $A$ and $C$ ). The lower boxed region in $(A)$ is magnified in $(B)$ and the upper boxed region is magnified in (C). In the adult rat, IGSF1 was present

in the choroid plexus both at the protein (D) and mRNA levels (E). $\mathrm{CP}$, choroid plexus; RP, Rathke's pouch; TV, third ventricle; LV, lateral ventricle; NC, notochord.

(e.g., in the paraventricular nucleus, supraoptic nucleus, medial preoptic nucleus, ventro- and dorso-medial nucleus), and the lowest expression in the lateral zone. Igsf1 mRNA was virtually absent in the posterior pituitary gland and in other parts of the brain, although low expression was observed in the cortex, subfornical organ, striatum, and amygdala (Supplementary Figure 1, see section on supplementary data given at the end of this article). mostly in Gfap-positive glial cells (mean \pm s.D.: $71.3 \pm 9.9 \%$ were considered Igsf1-positive; Fig. 3D), as well as in cells producing $T h(39.5 \pm 13.5 \%)$ or Ghrh $(18.6 \pm 26.3 \%)$. Igsf1 mRNA expression was low in Gad67-positive GABA-ergic cells $(8.4 \pm 9.5 \%)$, Vglut-positive cells (0\%), Vimentin-positive tanycytes (0\%), and cells producing Sst $(5.1 \pm 1.6 \%)$, Gnrh1 $(3.5 \pm 4.9 \%)$, Crh $(6.2 \pm 6.0 \%)$, or $\operatorname{Trh}(14.0 \pm 10.8 \%)$.
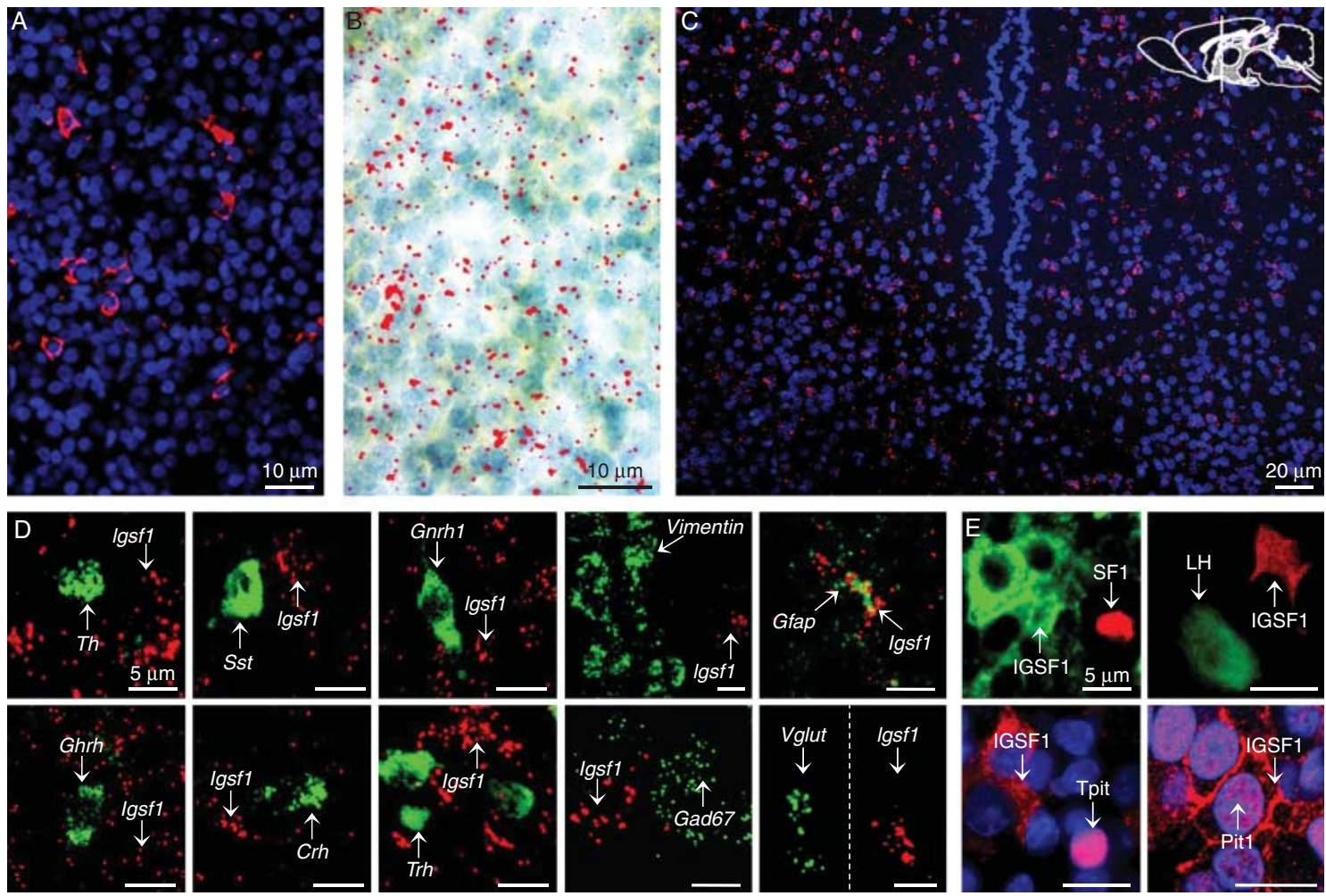

\section{Figure 3}

In the adult rat, IGSF1 was present in the pituitary gland at the protein (A) and mRNA levels (B). Igsf1 mRNA was expressed mostly in the periventricular and medial parts of the adult rat hypothalamus $(C)$, were it co-localized principally with GFAP (D). In the adult rat pituitary, IGSF1 protein co-localized mostly with PIT1 (E). TH, tyrosine hydroxylase; Gad67, glutamic acid decarboxylase 67; Vglut, vesicular glutamate transporter; GFAP, glial fibrillary acidic protein. 
In the pituitary, IGSF1 protein was observed in the vast majority of cells $(81 \pm 1.4 \%)$ of the PIT1-lineage (somatotropes, thyrotropes, and lactotropes; Fig. 3E). IGSF1 was absent in cells containing LH and SF1 (gonadotropes) or TPIT (corticotropes).

No sex differences were observed.

\section{Thorax}

High expression of Igsf1 mRNA was detected in the adult heart, and to a lesser extent in skeletal muscle (Fig. 1). Igsf1 mRNA expression was low in adult thyroid gland and absent in adult lung and thymus (Fig. 1).

We observed IGSF1 protein expression in the developing heart and skeletal striated muscle on ED15; the banded pattern in (cardio-)myocytes was consistent with the costameres (Fig. 4A and B). Costameres represent the structural-functional component connecting force-generating sarcomeres to the cell membrane (or 'sarcolemma') of striated muscle cells. A similar pattern was observed in the adult heart and skeletal muscle (Fig. 4C and D). No sex differences were observed.

We did not observe Igsf1 mRNA expression in the thyroid gland with in situ hybridization, and only noted low immunoreactive staining in the cytoplasm and nucleus of follicular cells (Supplementary Figure 2, see section on supplementary data given at the end of this article). Moreover, the Igsf1 mRNA observed with qPCR may reflect contamination with muscular tissue that surrounds the thyroid gland. We therefore consider IGSF1 expression in the thyroid gland to be very low, if present at all.

\section{Abdomen}

In the abdominal region, we observed Igsf1 mRNA expression in the adult adrenal gland (Fig. 1). Igsf1 mRNA expression was low in the pancreas and absent in the adult spleen, intestines, liver, kidney, prostate, and white and brown adipose tissue.

Immunohistochemical staining of IGSF1 protein was observed on ED15 in the adrenal gland, pancreas, and liver (Fig. 5A, B, and C). Expression in the liver was transient and disappeared the first days after birth (Fig. 5D), resulting in the absence of IGSF1 in adult liver at the protein (Fig. 5E) and mRNA levels (Fig. 1 and Supplementary Figure 3, see section on supplementary data given at the end of this article). In the adult pancreas, a faint staining of the IGSF1 protein was observed exclusively and homogeneously in the islets of Langerhans (Fig. 5F), but virtually no Igsf1 mRNA was observed with in situ hybridization (Fig. 5G). In the adult adrenal gland, IGSF1 protein (Fig. 5H) and mRNA (Fig. 5I) were both expressed solely in the zona glomerulosa of the cortex. No sex differences were observed.

\section{Gonads}

Igsf1 mRNA was detected in the adult testis, while it was virtually absent in the prostate and ovary (Fig. 1).

IGSF1 protein expression was not observed in the developing male gonads. However, within the seminiferous tubules of the adult testis, IGSF1 was expressed in Sertoli cells, but remarkably only during stages XIII through VI of the seminiferous epithelium (Fig. 6A, B, and C. For a schematic overview, see Supplemental Figure 4, see section on supplementary data given at the end of this article). Staining was observed throughout the cytoplasm of all Sertoli cells in those stages (and hardly or not in Sertoli cells in other stages), from the basal membrane to the luminal side of the seminiferous tubules. IGSF1 was absent in Sertoli cells of stages VII-XII (Fig. 6B and D). In developing germ cells, IGSF1 was present in the acrosome/nucleus of elongating spermatids during
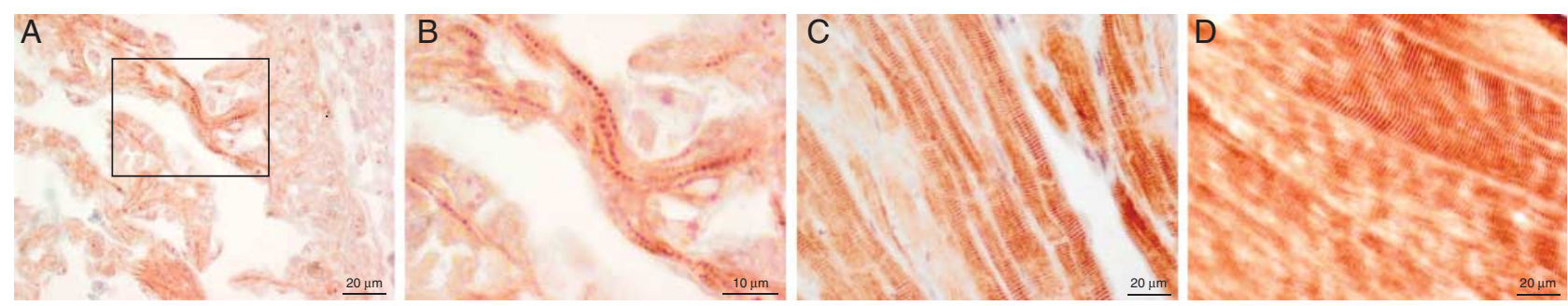

Figure 4

IGSF1 immunoreactivity was observed in the rat heart and skeletal muscles at embryonic day 15 (A and B) and in adult heart (C) and skeletal muscle (D). The boxed region in (A) is magnified in (B). The banded pattern in (cardio-)myocytes is consistent with the costameres. 

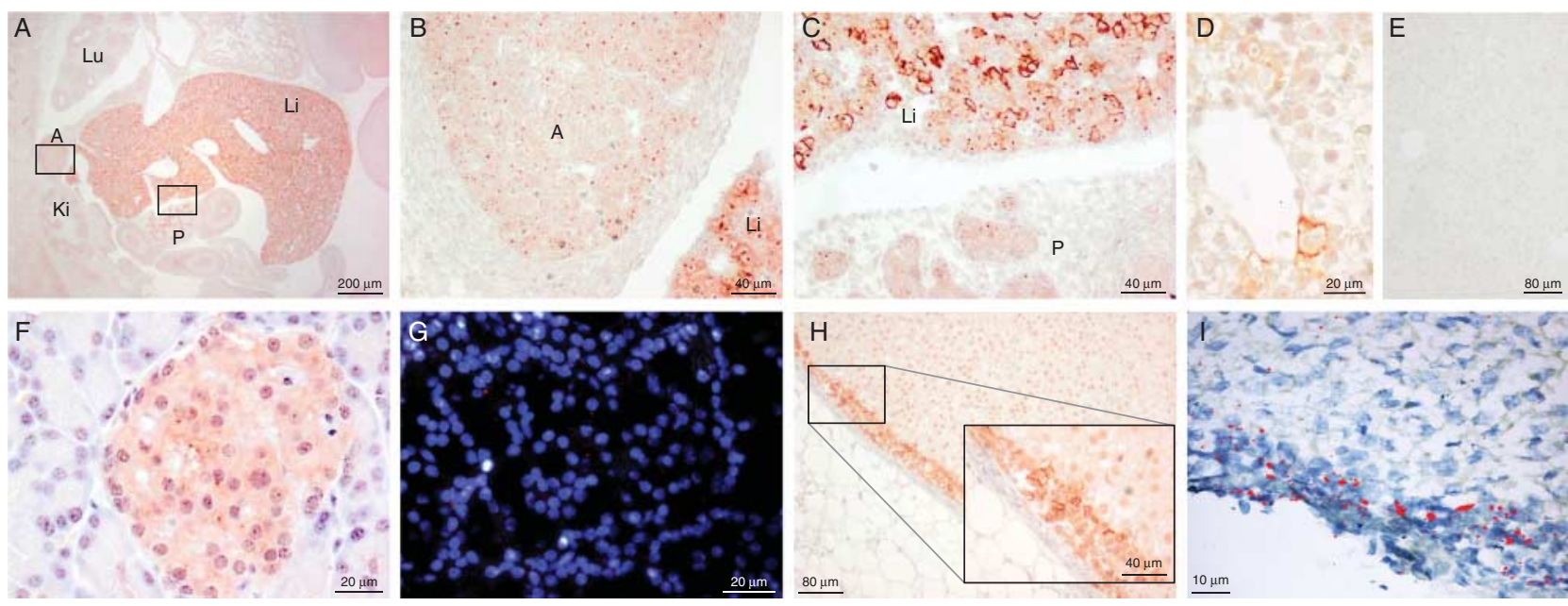

Figure 5

IGSF1 immunohistochemical staining was observed in the abdomen of rat at embryonic day 15 , mostly in the liver, adrenal gland, and pancreas (A, B, and C). The left boxed region in (A) is magnified in (B) and the right boxed region is magnified in (C). Expression in the liver was transient and disappeared the first days after birth (D), resulting in the absence of IGSF1

epithelial stages X through XIII (Fig. 6B and C), occasionally in early pachytene spermatocytes (Fig. 6A), and in germ granules when present in spermatocytes and elongating spermatids (Fig. 6C). In the interstitium, staining of adult Leydig cells was at background levels (Supplementary Figure 5A, see section on supplementary data given at the end of this article). IGSF1 was absent in Sertoli and Leydig cells when in a proliferative stage (13 and $17 \mathrm{dpp}$; Supplementary Figure 5B). Protein expression and localization in the testis was corroborated by expression at the mRNA level with in situ hybridization (Fig. 6D), showing high expression in Sertoli cells in many, but not all, seminiferous tubules and little to no expression in the interstitial Leydig cells. in adult liver at the protein (E). In the islets of Langerhans of the adult rat pancreas, IGSF1 was observed at the protein (F), but not at the mRNA level (G). In the adult rat adrenal gland, IGSF1 was confined to the zona glomerulosa of the cortex, both at the protein $(\mathrm{H})$ and mRNA level (I). Lu, lung; A, adrenal; Li, liver; Ki, kidney; P, pancreas.

\section{Discussion}

In this study, we investigated the organ and cell-type specific spatial and temporal expression of IGSF1 in the rat. Our results show that IGSF1 is expressed abundantly in the brain, specifically in the choroid plexus and glial cells of the hypothalamus; in somatotropes, thyrotropes, and lactotropes of the pituitary gland; the zona glomerulosa of the adrenal gland; the fetal liver; the costameres of myocytes in heart and skeletal muscle; and in the Sertoli cells and elongating spermatids of the testis. IGSF1 expression was low in the thyroid gland, ovary, and pancreas and absent in lung, adult liver, and adipose tissues. This is the first study to investigate spatial expression of IGSF1 throughout the body, although
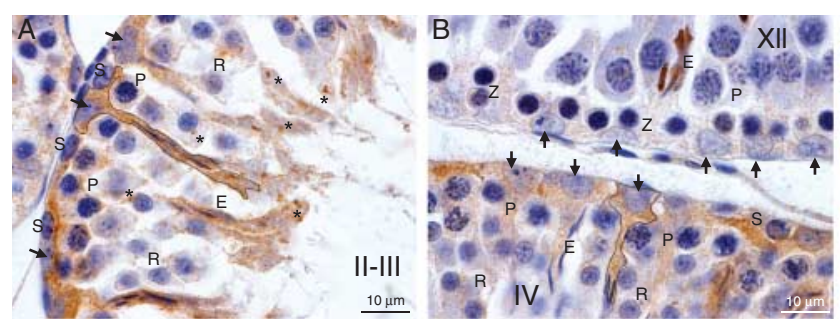
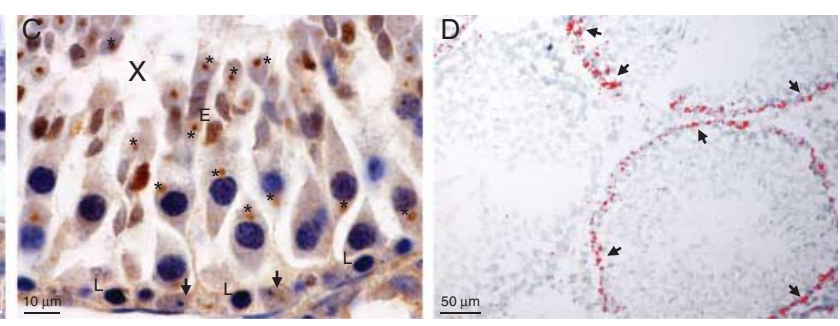

\section{Figure 6}

Variable expression IGSF1 protein was observed in adult rat testis during representative epithelial stages II-III (A), IV and XII (B), and X (C). Testicular protein expression was corroborated by detection of Igsf1 mRNA (D), showing high expression in Sertoli cells in many, but not all, seminiferous Printed in Great Britain
(C) 2015 Society for Endocrinology tubules and little to no expression in Leydig cells. Arrow, Sertoli cells; S, spermatogonia; L, leptotene spermatocytes; $Z$, zygotene spermatocytes; $P$, pachytene spermatocytes; $R$, round spermatids; $E$, elongating spermatids; *, germ granules.

Published by Bioscientifica Ltd. 
profiling of Igsf1 mRNA expression in human tissue homogenates has been reported in large-scale expression profiling arrays, showing expression in fetal liver, adult human testis, skeletal muscle, hypothalamus, and strongly in the pituitary gland, while it was absent in the adult liver, thyroid gland, adrenal, and ovary (NCBI GEO profiles ID 878068 (Su et al. 2002), 4687216 (Su et al. 2004), 69561877 (She et al. 2009), 10126516 (Ge et al. 2005), 49003493 (Dezso et al. 2008)).

Expression of IGSF1 in the PIT1-lineage of the pituitary gland is in line with the human clinical phenotype of IGSF1 deficiency, showing decreased freethyroxine $\left(\mathrm{T}_{4}\right)$ with inappropriately normal TSH levels (central hypothyroidism) in all male patients, decreased prolactin in most, and (transiently) decreased GH in some (Sun et al. 2012, Joustra et al. 2013). It is also consistent with the central hypothyroidism in IGSF1-deficient mice (Sun et al. 2012). It is, however, unknown whether this central hypothyroidism is caused by a defect in the hypothalamus, pituitary gland, or both, since no diagnostic tool (including the TRH stimulation test) can determine this with certainty (Persani 2012). TSH secretion is mainly influenced by feed-forward action of hypothalamic TRH and feedback of circulating thyroid hormones, but can be modulated by the negative effects of hypothalamic somatostatin and dopamine, glucocorticoids (Roelfsema \& Veldhuis 2013), and autocrine signals such as leptin and neuromedin B (Denef 2008). IGSF1's presence in pituitary thyrotropes and absence in hypothalamic TRH-producing neurons might indicate thyrotrope dysfunction in IGSF1 deficiency, e.g., decreased receptivity to endocrine or autocrine signaling, or impaired TSH synthesis and/or secretion capability. However, the absence of IGSF1 in hypophysiotropic TRH neurons does not rule out a role for the hypothalamus in the central hypothyroidism, since production of TRH relies on a complex and incompletely understood interaction with glial cells, which express Igsf1 mRNA. Glial cells are thought to convert $\mathrm{T}_{4}$ to tri-iodothyronine $\left(\mathrm{T}_{3}\right)$ using type-2 deiodinase, and 'present' $\mathrm{T}_{3}$ to the TRH neuron via MCT8 (Alkemade et al. 2005). Additionally, glial cells can degrade the TRH secreted in the medial eminence before it reaches the pituitary gland through the glial production of pyroglutamyl peptidase II (Fekete \& Lechan 2014). Tanycytes, the specialized glial cells lining the third ventricle responsible for $\mathrm{T}_{4}$ uptake from the CSF, did not show Igsf1 expression. However, we observed strong expression in the choroid plexus, involved with producing CSF and controlling macromolecule transport across the blood-CSF barrier. Future research on IGSF1's role in the hypothalamo-pituitary-thyroid axis should focus on the choroid plexus epithelial cells, hypothalamic glial cells, and pituitary thyrotropes. In humans, Igsf1 mRNA enrichment has been observed with microarrays in the hypothalamus and amygdala, while no evident enrichment was observed in the choroid plexus (Allen Human Brain Atlas; Hawrylycz et al. 2012).

Cell-type specific localization of IGSF1 in the hypothalamus and pituitary gland has not been studied in any adult species before. Our results are in concordance with previous reports of Igsf 1 mRNA expression in homogenates of adult pituitary of rat (Sun et al. 2012), mouse (Sun et al. 2012), human (Sun et al. 2012), and sheep (Fafioffe et al. 2004), as well as the adult human brain (Frattini et al. 1998, Mazzarella et al. 1998). Furthermore, our observations concur with two previous studies that used in situ hybridization (although without assessing co-localization) and reported Igsf1 mRNA expression in most cells of the anterior pituitary of adult rat (Bernard \& Woodruff 2001), embryonic mouse (Sun et al. 2012), and embryonic human (Sun et al. 2012). IGSF1 protein expression in pituitary homogenates was previously reported in adult mice (Sun et al. 2012) and humans (Chapman \& Woodruff 2001). Immunohistochemical staining was previously demonstrated in adult human pituitary tissue (Faucz et al. 2015), but co-localization was only assessed in embryonic mouse pituitary. IGSF1 expression was observed in thyrotropes, somatotropes, and lactotropes, but not gonadotropes (Sun et al. 2012), which is consistent with our results in the adult rat. However, increased amounts of Igsf 1 mRNA have been observed in pituitary adenoma secreting GH or prolactin, while decreased amounts were observed in those secreting ACTH or gonadotropins (NCBI GEO profiles ID 11104016 (Morris et al. 2005), 83167537 (Michaelis et al. 2011)), in accordance with the PIT1 lineage.

Besides congenital central hypothyroidism, male patients with IGSF1 deficiency show a delayed pubertal rise of testosterone and a subsequent delay of the linear growth spurt and development of secondary sex characteristics. Remarkably, the pubertal increase in testicular size is normal, but the testes continue to grow into adulthood, resulting in macroorchidism in all adult patients (Joustra et al. 2013). Our observation of IGSF1 in the Sertoli cells of the testis, but not in the gonadotropes or GnRH-producing neurons, and the previous observation of a normal $\mathrm{LH}$ response to $\mathrm{GnRH}$ in a limited number of patients tested in early puberty (Sun et al. 2012), point towards a local defect in the testis. However, complete assessment of the complex neuroendocrine regulation of puberty and reproduction is beyond the

Published by Bioscientifica Ltd 
scope of this study. Decreased sensitivity of the Leydig and Sertoli cells to thyroid hormone could explain the delayed testosterone rise (through inhibition of the $\mathrm{T}_{3}$-dependent increase in LH receptors) and macroorchidism (through prolonged duration of Sertoli cell proliferation) (Weber et al. 2003). However, a modulating role for IGSF1 in FSH sensitivity, which determines the proliferation rate of Sertoli cells, could also explain the macroorchidism. Interestingly, the Sertoli cells in rat are preferentially sensitive to FSH during stages XIII through $\mathrm{V}$ of the seminiferous epithelium (Parvinen 1982), which coincides with the observed temporal IGSF1 expression pattern. Sensitivity to androgens, on the other hand, is highest at stages VII-VIII (Parvinen 1982), when IGSF1 is absent. Lastly, Leydig cells are known to produce TRH, which locally stimulates Leydig cell development and regulates testosterone secretion, independent of thyroid hormone state (Mendis-Handagama \& Siril Ariyaratne 2005). Although IGSF1 was expressed only in low levels in Leydig cells, Sertoli cells can influence Leydig cell function through paracrine signaling (Lejeune et al. 1992). It is unknown whether TRH receptor (Trhr1) mRNA expression in Leydig cells is decreased in $\operatorname{Ig} s f 1^{\Delta \mathrm{ex} 1}$ mice, as occurs in the pituitary of these mice (Sun et al. 2012). Future research should focus on IGSF1's stage-specific role in Sertoli cells of the testis.

Furthermore, IGSF1 was expressed in elongating spermatids. At least 17 other members of the immunoglobulin superfamily are expressed at the membrane of germ cells or spermatozoa (as well as Sertoli cells), where they play roles in cell adhesion or sperm-egg interaction (Toshimori 2009). Knockout of these genes often results in decreased fertility (Toshimori 2009). However, based on their pedigree, IGSF1-deficient male patients do not show severely decreased fertility, suggesting redundancy of IGSF1 in germ cell development.

The current study is the first to assess IGSF1 expression in testis histologically. Our results are in line with reports of Igsf1 mRNA expression in testis homogenates of adult rat (Bernard \& Woodruff 2001), adult sheep (Fafioffe et al. 2004), and humans (Frattini et al. 1998, Mazzarella et al. 1998). One study assessed protein expression with western blot and observed no IGSF1 protein in the testis of adult mice (Sun et al. 2012), which could be explained by a species- or strain-specific finding, absence of the epitope, or tissue-specific splicing. The absence of Igsf 1 mRNA in the ovary is in line with two previous reports using northern blot (Bernard \& Woodruff 2001, Mazzarella et al. 1998).

Our observation of IGSF1 in the zona glomerulosa of the adrenal gland and pancreas cannot be linked directly to the clinical phenotype of IGSF1 deficiency in humans, as no signs of altered aldosterone production or carbohydrate homeostasis were observed in patients. Also, Igsf1 mRNA could not be detected with in situ hybridization in the pancreas, despite its presence by qPCR. This could be a sensitivity problem of in situ hybridization when mRNA expression is low. Despite the unknown relevance of IGSF1 in adrenal gland and pancreas, neuroendocrine properties of the adrenal gland have been attributed to the expression of other members of the immunoglobulin superfamily, such as the neuronal cell adhesion molecules (NCAMs), which are observed specifically in the zona glomerulosa (as well as pituitary gland (Lahr et al. 1993) and islets of Langerhans (Lahr et al. 1993)) and are involved in cell-cell interactions (Ehrhart-Bornstein \& Hilbers 1998). Furthermore, most serum TRH originates from the islets of Langerhans (Kawano et al. 1983). Disruption of the TRH gene is associated with hyperglycemia and impaired insulin secretion in response to glucose (Yamada et al. 1997). Chronic TRH administration, on the other hand, produces pancreatic hyperplasia (Glasbrenner et al. 1990) and reverses the diabetes mellitus observed after damaging the islets of Langerhans in rats (Luo \& Jackson 2007). TRH is also produced by the rat adrenal cortex and acts locally as a growth factor, especially in the zona glomerulosa (ZerekMelen \& Pawlikowski 1996). As Trhr1 mRNA is decreased in the pituitary of Igsf $1^{\Delta \mathrm{ex} 1}$ mice (Sun et al. 2012), IGSF1 might regulate TRH action in the adrenal gland and pancreas. Our results corroborate those of an early study showing Igsf 1 mRNA expression in adult rat adrenal gland (Bernard \& Woodruff 2001). Moreover, both reports suggest that the transcript is derived from an intronic promoter and corresponds to mRNA isoform 4 described in mouse pituitary (Bernard et al. 2003). The rat pancreas has not been investigated previously, but IGSF1 mRNA expression has been observed in northern blots of the adult human pancreas (Frattini et al. 1998, Mazzarella et al. 1998).

IGSF1 was also present in the embryonic liver, but decreased rapidly after birth, suggesting a role in a liver function specific to the fetal period (e.g., hematopoiesis). One study reported IGSF1 expression in human hepatocellular carcinoma, implying that the silenced expression of postnatal IGSF1 might be reversible in disease (Patil et al. 2005). Although the fetal rat liver has not been investigated before, our results are in line with previous reports of Igsf 1 mRNA expression in northern blots of fetal human liver (Frattini et al. 1998, Mazzarella et al. 1998) and its absence in the adult rat and human liver (Frattini et al. 1998, Mazzarella et al. 1998, Chong et al. 2000, Bernard \& Woodruff 2001).

Published by Bioscientifica Ltd 
Unexpectedly, IGSF1 was observed in the costameres of the cardiac and skeletal muscles. Costameres are part of the cortical cytoskeleton of striated muscle cells and connect the force-generating sarcomeres to the cell membrane, and are therefore a critical element of the myocyte (Ervasti 2003). Notably, Trh gene transcription has been observed in rat heart and striated muscle, where it enhances myocyte contractility in a paracrine or autocrine way (Shi et al. 1996). However, IGSF1 deficient patients do not exhibit overt (cardio-)myopathies, which might be explained by genetic redundancy and may be subject to future study. IGSF1 has not been investigated in rat muscle before, but our results are in line with reports of IGSF1 mRNA expression in northern blots of adult human heart and skeletal muscle (Frattini et al. 1998, Mazzarella et al. 1998).

Inherent to expression profiling, the results of our study are limited by the sensitivity and specificity of the techniques used. Furthermore, we must bear in mind that not all cell types present in the hypothalamus and pituitary gland were studied for co-expression, since there are simply too many. Lastly, one must take into account that both testicular function and maturation as well as pituitary hormone secretion are influenced by local paracrine crosstalk (Denef 2008). Therefore, functioning of cells that do not express IGSF1 can still be influenced by IGSF1 on neighboring cells.

In conclusion, we observed expression of IGSF1 in thyrotropes, somatotropes, and lactotropes of the pituitary and in Sertoli cells of the testis. This expression is consistent with deficiency of $\mathrm{GH}$, TSH, and prolactin, delayed pubertal testosterone production, and macroorchidism observed in patients with IGSF1 deficiency. The expression in the choroid plexus and glial cells of the hypothalamus provokes novel hypotheses on the pathophysiology of the central hypothyroidism. IGSF1's function in the adrenal gland, pancreas, fetal liver, and striated muscles cells may be subject of future research. Together, the results of this study will facilitate future research on IGSF1's place in endocrine physiology by providing insight into relevant tissues and cell types.

\section{Supplementary data}

This is linked to the online version of the paper at http://dx.doi.org/10.1530/ JOE-15-0204.

\section{Declaration of interest}

The authors declare that there is no conflict of interest that could be perceived as prejudicing the impartiality of the research reported.

\section{Funding}

The study was supported by an unrestricted research grant from Ipsen Farmaceutica BV. D J B is supported by CIHR MOP- 133557.

\section{Acknowledgements}

The authors acknowledge Dr M R Boon for her help in resecting the thyroid gland and Dr I Zalachoras for his help with the qPCR of brain regions.

\section{References}

Alkemade A, Friesema EC, Unmehopa UA, Fabriek BO, Kuiper GG, Leonard JL, Wiersinga WM, Swaab DF, Visser TJ \& Fliers E 2005 Neuroanatomical pathways for thyroid hormone feedback in the human hypothalamus. Journal of Clinical Endocrinology and Metabolism 90 4322-4334. (doi:10.1210/jc.2004-2567)

Bernard DJ \& Woodruff TK 2001 Inhibin binding protein in rats: alternative transcripts and regulation in the pituitary across the estrous cycle. Molecular Endocrinology 15 654-667. (doi:10.1210/mend.15.4.0630)

Bernard DJ, Burns KH, Haupt B, Matzuk MM \& Woodruff TK 2003 Normal reproductive function in InhBP/p120-deficient mice. Molecular and Cellular Biology 23 4882-4891. (doi:10.1128/MCB.23.14.4882-4891.2003)

Chapman SC \& Woodruff TK 2001 Modulation of activin signal transduction by inhibin B and inhibin-binding protein (INhBP). Molecular Endocrinology 15 668-679. (doi:10.1210/mend.15.4.0616)

Chong H, Pangas SA, Bernard DJ, Wang E, Gitch J, Chen W, Draper LB, Cox ET \& Woodruff TK 2000 Structure and expression of a membrane component of the inhibin receptor system. Endocrinology 141 2600-2607. (doi:10.1210/endo.141.7.7540)

Denef C 2008 Paracrinicity: the story of 30 years of cellular pituitary crosstalk. Journal of Neuroendocrinology 20 1-70. (doi:10.1111/j.13652826.2008.01676.x)

Dezso Z, Nikolsky Y, Sviridov E, Shi W, Serebriyskaya T, Dosymbekov D, Bugrim A, Rakhmatulin E, Brennan RJ, Guryanov A et al. 2008 A comprehensive functional analysis of tissue specificity of human gene expression. BMC Biology 6 49. (doi:10.1186/1741-7007-6-49)

Ehrhart-Bornstein M \& Hilbers U 1998 Neuroendocrine properties of adrenocortical cells. Hormone and Metabolic Research 30 436-439. (doi:10.1055/s-2007-978911)

Ervasti JM 2003 Costameres: the Achilles' heel of Herculean muscle. Journal of Biological Chemistry 278 13591-13594. (doi:10.1074/jbc.R200021200)

Fafioffe A, Ethier JF, Fontaine J, JeanPierre E, Taragnat C \& Dupont J 2004 Activin and inhibin receptor gene expression in the ewe pituitary throughout the oestrous cycle. Journal of Endocrinology 182 55-68. (doi:10.1677/joe.0.1820055)

Faucz FR, Horvath AD, Azevedo MF, Levy I, Bak B, Wang Y, Xekouki P, Szarek E, Gourgari E, Manning AD et al. 2015 Is IGSF1 involved in human pituitary tumor formation? Endocrine-Related Cancer 22 47-54. (doi:10.1530/ERC-14-0465)

Fekete C \& Lechan RM 2014 Central regulation of hypothalamic-pituitarythyroid axis under physiological and pathophysiological conditions. Endocrine Reviews 35 159-194. (doi:10.1210/er.2013-1087)

Frattini A, Faranda S, Redolfi E, Allavena P \& Vezzoni P 1998 Identification and genomic organization of a gene coding for a new member of the cell adhesion molecule family mapping to Xq25. Gene 214 1-6. (doi:10.1016/S0378-1119(98)00253-4)

Ge X, Yamamoto S, Tsutsumi S, Midorikawa Y, Ihara S, Wang SM \& Aburatani H 2005 Interpreting expression profiles of cancers by genome-wide survey of breadth of expression in normal tissues. Genomics 86 127-141. (doi:10.1016/j.ygeno.2005.04.008)

Glasbrenner B, Malfertheiner P, Duntas L, Buchler M, Bereiter T \& Ditschuneit H 1990 Effects of TRH on pancreatic growth and secretion in rats. Pancreas 5 37-41. (doi:10.1097/00006676-199001000-00005) 
Hawrylycz MJ, Lein ES, Guillozet-Bongaarts AL, Shen EH, Ng L, Miller JA, van de Lagemaat LN, Smith KA, Ebbert A, Riley ZL et al. 2012 An anatomically comprehensive atlas of the adult human brain transcriptome. Nature 489 391-399. (doi:10.1038/nature11405)

Joustra SD, Schoenmakers N, Persani L, Campi I, Bonomi M, Radetti G, Beck-Peccoz P, Zhu H, Davis TM, Sun Y et al. 2013 The IGSF1 deficiency syndrome: characteristics of male and female patients. Journal of Clinical Endocrinology and Metabolism 98 4942-4952. (doi:10. 1210/jc.2013-2743)

Kawano H, Daikoku S \& Saito S 1983 Location of thyrotropin-releasing hormone-like immunoreactivity in rat pancreas. Endocrinology 112 951-955. (doi:10.1210/endo-112-3-951)

Lahr G, Mayerhofer A, Bucher S, Barthels D, Wille W \& Gratzl M 1993 Neural cell adhesion molecules in rat endocrine tissues and tumor cells: distribution and molecular analysis. Endocrinology 132 1207-1217. (doi:10.1210/endo.132.3.8440182)

Lejeune H, Skalli M, Chatelain PG, Avallet O \& Saez JM 1992 The paracrine role of Sertoli cells on Leydig cell function. Cell Biology and Toxicology $\mathbf{8}$ 73-83. (doi:10.1007/BF00130513)

Luo LG \& Jackson I 2007 Thyrotropin releasing hormone (TRH) may preserve pancreatic islet cell function: potential role in the treatment of diabetes mellitus. Acta Bio-Medica 78(Suppl 1) 216-221.

Mazzarella R, Pengue G, Jones J, Jones C \& Schlessinger D 1998 Cloning and expression of an immunoglobulin superfamily gene (IGSF1) in Xq25. Genomics 48 157-162. (doi:10.1006/geno.1997.5156)

Mendis-Handagama SM \& Siril Ariyaratne HB 2005 Leydig cells, thyroid hormones and steroidogenesis. Indian Journal of Experimental Biology $\mathbf{4 3}$ 939-962.

Michaelis KA, Knox AJ, Xu M, Kiseljak-Vassiliades K, Edwards MG, Geraci M, Kleinschmidt-Demasters BK, Lillehei KO \& Wierman ME 2011 Identification of growth arrest and DNA-damage-inducible gene $\beta$ (GADD $45 \beta$ ) as a novel tumor suppressor in pituitary gonadotrope tumors. Endocrinology 152 3603-3613. (doi:10.1210/en.2011-0109)

Morris DG, Musat M, Czirjak S, Hanzely Z, Lillington DM, Korbonits M \& Grossman AB 2005 Differential gene expression in pituitary adenomas by oligonucleotide array analysis. European Journal of Endocrinology 153 143-151. (doi:10.1530/eje.1.01937)

Parvinen M 1982 Regulation of the seminiferous epithelium. Endocrine Reviews 3 404-417. (doi:10.1210/edrv-3-4-404)

Patil MA, Chua MS, Pan KH, Lin R, Lih CJ, Cheung ST, Ho C, Li R, Fan ST, Cohen SN et al. 2005 An integrated data analysis approach to characterize genes highly expressed in hepatocellular carcinoma. Oncogene 24 3737-3747. (doi:10.1038/sj.onc.1208479)

Paxinos G, Franklin K. 1988 The rat brain in stereotactic coordinates. Orlando, FL: Academic Press, Elsevier.

Persani L 2012 Clinical review: Central hypothyroidism: pathogenic, diagnostic, and therapeutic challenges. Journal of Clinical Endocrinology and Metabolism 97 3068-3078. (doi:10.1210/jc.2012-1616)

Pfaffl MW 2001 A new mathematical model for relative quantification in realtime RT-PCR. Nucleic Acids Research 29 e45. (doi:10.1093/nar/29.9.e45)

Robakis T, Bak B, Lin SH, Bernard DJ \& Scheiffele P 2008 An internal signal sequence directs intramembrane proteolysis of a cellular immunoglobulin domain protein. Journal of Biological Chemistry $\mathbf{2 8 3}$ 36369-36376. (doi:10.1074/jbc.M807527200)

Roelfsema F \& Veldhuis JD 2013 Thyrotropin secretion patterns in health and disease. Endocrine Reviews 34 619-657. (doi:10.1210/er.2012-1076)

She X, RohlCA, Castle JC, Kulkarni AV, Johnson JM \& Chen R 2009 Definition, conservation and epigenetics of housekeeping and tissue-enriched genes. BMC Genomics 10 269. (doi:10.1186/1471-2164-10-269)

Shi ZX, Xu W, Mergner WJ, Li QL, Cole KH \& Wilber JF 1996 Localization of thyrotropin-releasing hormone mRNA expression in the rat heart by in situ hybridization histochemistry. Pathobiology 64 314-319. (doi:10.1159/000164066)

Su AI, Cooke MP, Ching KA, Hakak Y, Walker JR, Wiltshire T, Orth AP, Vega RG, Sapinoso LM, Moqrich A et al. 2002 Large-scale analysis of the human and mouse transcriptomes. PNAS 99 4465-4470. (doi:10.1073/ pnas.012025199)

Su AI, Wiltshire T, Batalov S, Lapp H, Ching KA, Block D, Zhang J, Soden R, Hayakawa M, Kreiman G et al. 2004 A gene atlas of the mouse and human protein-encoding transcriptomes. PNAS 101 6062-6067. (doi:10.1073/pnas.0400782101)

Sun Y, Bak B, Schoenmakers N, van Trotsenburg AS, Oostdijk W, Voshol P, Cambridge E, White JK, le Tissier P, Gharavy SN et al. 2012 Loss-of-function mutations in IGSF1 cause an X-linked syndrome of central hypothyroidism and testicular enlargement. Nature Genetics $\mathbf{4 4}$ 1375-1381. (doi:10.1038/ng.2453)

Toshimori K. 2009 Sperm-Head formation and Factors Affecting It. In In: Dynamics of the Mammalian Sperm Head, pp 23-25. Springer-Verlag.

Voss JW, Yao TP \& Rosenfeld MG 1991 Alternative translation initiation site usage results in two structurally distinct forms of Pit-1. Journal of Biological Chemistry 266 12832-12835.

Wagenaar GT, ter Horst SA, van Gastelen MA, Leijser LM, Mauad T, van der Velden PA, de Heer E, Hiemstra PS, Poorthuis BJ \& Walther FJ 2004 Gene expression profile and histopathology of experimental bronchopulmonary dysplasia induced by prolonged oxidative stress. Free Radical Biology \& Medicine 36 782-801. (doi:10.1016/j.freeradbiomed.2003.12.007)

Wagenaar GT, Laghmani eH, Fidder M, Sengers RM, de Visser YP, de Vries L, Rink R, Roks AJ, Folkerts G \& Walther FJ 2013 Agonists of MAS oncogene and angiotensin II type 2 receptors attenuate cardiopulmonary disease in rats with neonatal hyperoxia-induced lung injury. American Journal of Physiology. Lung Cellular and Molecular Physiology 305 L341-L351. (doi:10.1152/ajplung.00360.2012)

Weber G, Vigone MC, Stroppa L \& Chiumello G 2003 Thyroid function and puberty. Journal of Pediatric Endocrinology and Metabolism 16(Suppl 2) 253-257.

Yamada M, Saga Y, Shibusawa N, Hirato J, Murakami M, Iwasaki T, Hashimoto K, Satoh T, Wakabayashi K, Taketo MM et al. 1997 Tertiary hypothyroidism and hyperglycemia in mice with targeted disruption of the thyrotropin-releasing hormone gene. PNAS 94 10862-10867. (doi:10.1073/pnas.94.20.10862)

Zerek-Melen G \& Pawlikowski M 1996 Effects of TRH and TRH-like peptide pGLU-HIS-GLY-NH(2) on adrenocortical cell proliferation in rats. Endocrine 5 179-182. (doi:10.1007/BF02738704)

Received in final form 28 June 2015

Accepted 10 July 2015

Accepted Preprint published online 10 July 2015 http://joe.endocrinology-journals.org

DOI: $10.1530 / J O E-15-0204$
(C) 2015 Society for Endocrinology Printed in Great Britain
Published by Bioscientifica Ltd. 